\title{
Practical Guide to the Design, Fabrication, and Calibration of NIST Nanocalorimeters
}

\author{
Feng $\mathbf{Y i}^{1}$, Michael D. Grapes ${ }^{2}$, and David A. LaVan ${ }^{1}$ \\ ${ }^{1}$ National Institute of Standards and Technology, \\ Gaithersburg, MD 20899, USA \\ ${ }^{2}$ Lawrence Livermore National Laboratory, \\ Livermore, CA 94550, USA \\ feng.yi@nist.gov \\ grapes2@llnl.gov \\ david.lavan@nist.gov
}

\begin{abstract}
We report here on the design, fabrication, and calibration of nanocalorimeter sensors used in the National Institute of Standards and Technology (NIST) Nanocalorimetry Measurements Project. These small-scale thermal analysis instruments are produced using silicon microfabrication approaches. A single platinum line serves as both the heater and temperature sensor, and it is made from a $500 \mu \mathrm{m}$ wide, $100 \mathrm{~nm}$ thick platinum trace, suspended on a $100 \mathrm{~nm}$ thick silicon nitride membrane for thermal isolation. Supplemental materials to this article (available online) include drawing files and LabVIEW code used in the fabrication and calibration process.
\end{abstract}

Key words: calibration; calorimeter; fabrication; fast scan; heater; nanocalorimeter; nanocalorimetry; platinum; process; thermal analysis; thermometer; thin film.

Accepted: August 22, 2019

Published: December 16, 2019

https://doi.org/10.6028/jres.124.021

\section{Introduction}

The Nanocalorimetry Measurements Project at the National Institute of Standards and Technology (NIST) has been studying the design, fabrication, and calibration of nanocalorimeter sensor chips for high-rate, highsensitivity thermal measurements of materials properties [1-16]. The sensor commonly used in this project is based on a design originally proposed by Allen et al. [7, 17-27]. We recently published an exhaustive review of nanocalorimetry [28] that highlights past trends and future directions in the field.

This work is intended to summarize and teach the details of our fabrication and calibration process, with sufficient information, including copies of our code, in the online supplemental materials to enable a reader to design and fabricate their own nanocalorimeters and create their own calibration system. ${ }^{1}$

Microhotplates are similar in design to nanocalorimeters but are often used for gas-phase analysis. Despite the growing interest in small-scale thermal measurements, there has been limited work on calibration of nanocalorimeters [8, 29-37] or microhotplates [38-44], which is one reason NIST has been active in this field.

Nanocalorimetry has been used to characterize many classes of materials. It can measure very small sample sizes, which is useful for samples that can be hazardous in bulk quantities, such as reactive or energetic materials, and samples that only exist in small scales, such as thin films and nanomaterials, among others. Readers interested in a thorough review of applications of nanocalorimetry should see Ref. [28].

NIST's efforts related to nanocalorimeters have included a focus on calibration and improvements to the sensor design to reduce the temperature distribution in the active area [45]. Further, we have been working on

${ }^{1}$ Nanocalorimeter fabrication was performed in part at the NIST Center for Nanoscale Science \& Technology (CNST). 
improvements to sample deposition and uniformity [14]. This work, though, is focused on the fabrication and calibration of nanocalorimeters and describes our efforts to design a nanocalorimeter sensor, develop a process to produce those sensors at NIST, and methods to calibrate each sensor using an automated LabVIEW ${ }^{2}$ virtual instrument. The supplemental materials available online include drawing files that may be used to produce masks for lithography, as well as the LabVIEW code used to calibrate the sensor chips.

\section{Design}

The sensor design is shown in Fig. 1. The electrical pads on the ends connect to a current loop, and the pads towards the sides allow for the measurement of the voltage drop across the active region of the sensor. The current and voltage recordings are converted to power and resistance, and the resistance values are converted to temperature based on a calibration described later.

Grooves are etched in the back that define the die shape, to help with die cleavage; they are etched during the deep potassium hydroxide $(\mathrm{KOH})$ etch step, which is used to release the membrane that defines the center of the sensor.

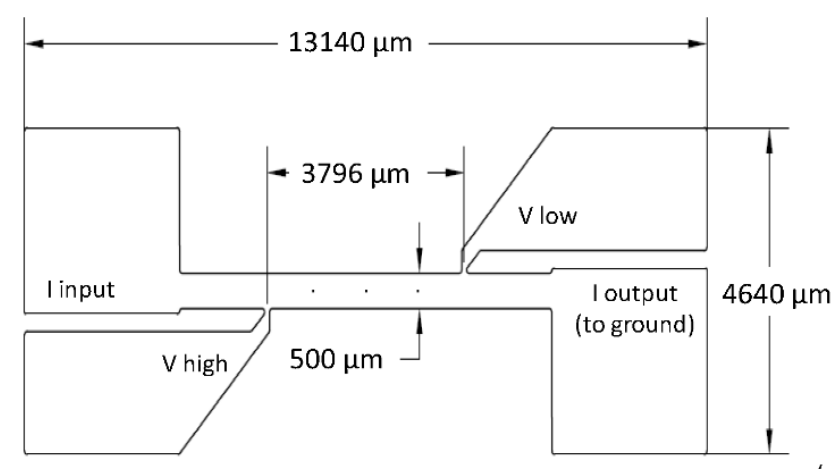

(a)
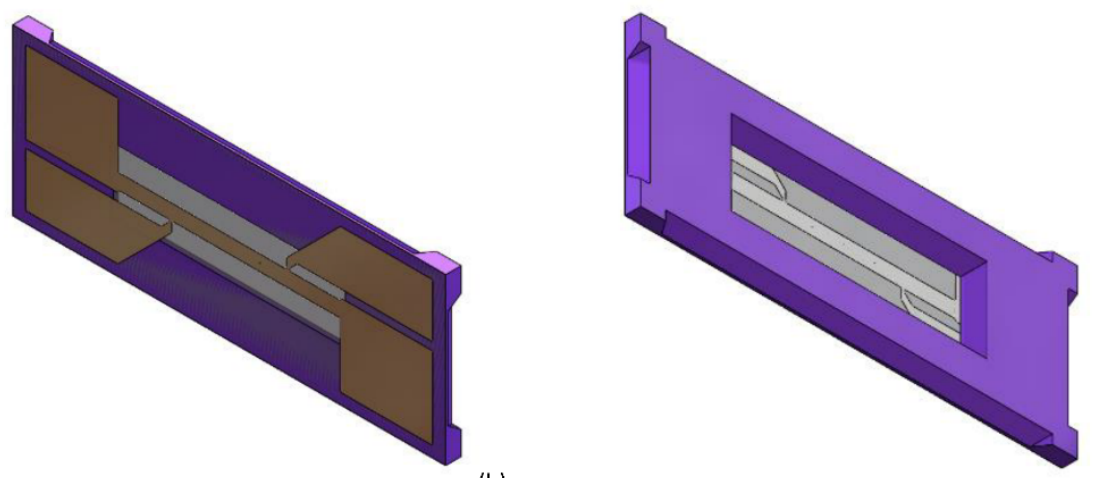

(b)

(c)

Fig. 1. Illustrations of the sensor. The overall die size is $4.8 \mathrm{~mm} \times 13.4 \mathrm{~mm}$. The heater is $500 \mu \mathrm{m}$ wide in the center. The spacing between the voltage probes (V high, V low) is $3700 \mu \mathrm{m}$ inside-edge-to-inside-edge or $3796 \mu \mathrm{m}$ center-to-center. The current input (I input) and current output (I output) are marked on the drawing. (a) AutoCAD drawing of metal layer of the mask, with units in $\mu$ m. (b) Isometric three-dimensional (3D) Solidworks model showing the front of the die. (c) Isometric 3D Solidworks model showing the back of the die. (drawing files are in the supplemental materials.)

\footnotetext{
${ }^{2}$ Certain commercial equipment, instruments, or materials are identified in this document. Such identification does not imply recommendation or endorsement by the National Institute of Standards and Technology, nor does it imply that the products identified are necessarily the best available for the purpose.
} 


\section{Fabrication Process}

The general strategy for the fabrication of the nanocalorimeters is to start with a standard $100 \mathrm{~mm}$ wafer, clean it thoroughly, grow $100 \mathrm{~nm}$ of low-stress silicon nitride on the front and back, pattern the platinum heater/temperature sensor on the front with a tantalum (Ta) adhesion layer, use reactive ion etching to open windows in the silicon nitride on the back, and then use $\mathrm{KOH}$ to deep etch from the back, through the silicon wafer, stopping at the front-side silicon nitride layer, followed by dicing, annealing, and calibration. Previous iterations of the design included steps where photoresist was applied to the front or back to protect the wafer while handling. We found this was not necessary and risked contaminating the platinum surface. The process details, including the tools, times, temperatures, etc., are included in the supplemental information, available online. This process has been used for the nanocalorimeters reported in our previous work.

\section{Annealing}

We have studied the annealing environment in detail, after discovering an anomaly in sensor performance that depended on the annealing furnace that was used; this anomaly was eventually attributed to the differences in annealing gas purity. Annealing in high-vacuum or ultrahigh-purity (UHP) inert gas leads to rapid grain growth and dewetting of the platinum from the surface, with progressively worse performance with subsequent thermal cycles. Metals deposited onto silicon nitride have poor adhesion, so a thin layer (often $10 \mathrm{~nm}$ ) is used between the platinum and silicon nitride to improve adhesion. Tantalum adhesion layers perform significantly better than titanium adhesion layers. Annealing in air or commercial-grade inert gas (we use argon) with small amounts of oxygen (at least $0.1 \%$ ) produces a more stable microstructure and stable resistance with multiple heating cycles [15].

Each sensor is annealed in a quartz tube furnace at $750{ }^{\circ} \mathrm{C}$ for $20 \mathrm{~min}$ in air, with a heating ramp of $25^{\circ} \mathrm{C} / \mathrm{min}$ and natural cooling. Breathing-quality air (this is a commercial designation for air with limited carbon dioxide, carbon monoxide, particulate content, and hydrocarbon content) is used with a flow rate of $200 \mathrm{~mL} / \mathrm{min}$, per the results of Ref. [15].

\section{Calibration}

We have published details on the design and evaluation of the calibration instrument we developed [8]. The general approach is to measure and record the resistance at room temperature, followed by resistance measurements during several cycles from roughly $300^{\circ} \mathrm{C}$ to $700^{\circ} \mathrm{C}$, followed by an additional resistance measurement at room temperature. This last measurement is a quality check to confirm that (1) there was no damage to the sensor, (2) there were no changes to the electrical contacts during the measurements, and (3) the sensor temperature coefficient of resistance (TCR) has stabilized.

All electrical measurements were made using a National Instruments PXI-4130 Source Measure Unit in a PXI-1033 chassis, operated from a workstation running Windows 7. LabVIEW was used for data collection and instrument control. Details of the calibration procedure and the LabVIEW code are available in the supplemental materials. Thermal measurements at elevated temperatures were made with a customized fiberoptic pyrometer (Optitherm III by the Pyrometer Instrument Company).

\subsection{Room-Temperature Resistance Measurements}

These sensors heat with very small applied currents (anything above $20 \mathrm{~mA}$ causes noticeable heating) and are therefore very sensitive to the measurement technique when measuring resistance at room temperature. To find the room-temperature resistance independent of self-heating and voltage offsets, we apply small currents, usually over the range of $1 \mathrm{~mA}$ to $3 \mathrm{~mA}$, in 20 equal steps. Figures 2 and 3 show this approach and include extra measurements up to $11 \mathrm{~mA}$ to illustrate some of the measurement challenges. Current is applied to the circuit, the voltage difference across the voltage probes is measured (this a classic four-wire resistance measurement across the sensor), and the values at each step are recorded. 


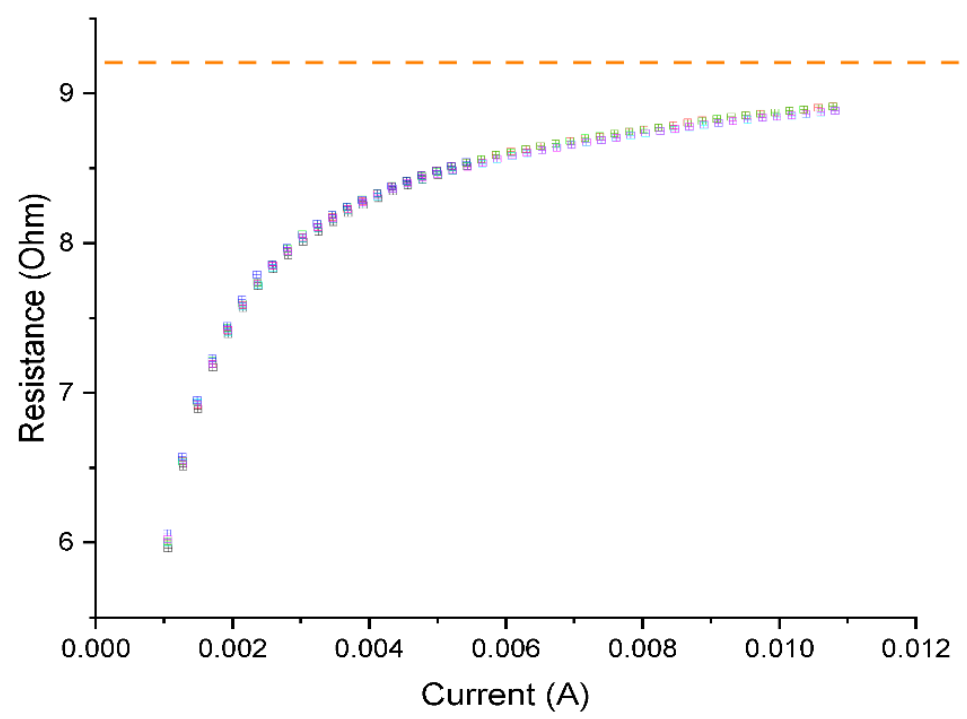

Fig. 2. Data from six room-temperature measurement cycles on one sensor showing resistance as a function of applied current, from $1 \mathrm{~mA}$ to $11 \mathrm{~mA}$. The orange dashed line is the value extracted from the slope of Fig. 3, which is taken as the true room-temperature resistance.

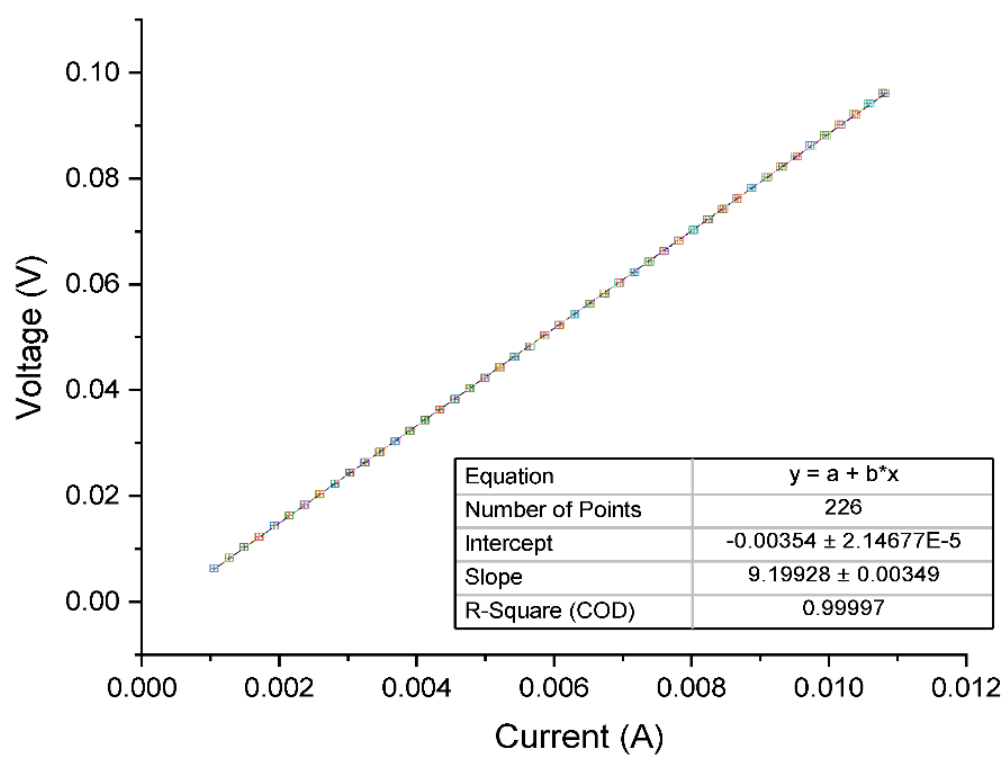

Fig. 3. Data from six room-temperature measurement cycles on one sensor (the same measurements as Fig. 2) plotted as voltage vs. current, where all measurements were made with currents below $11 \mathrm{~mA}$. Resistance, represented as the slope of this fit, is found to be the best value for the room-temperature resistance, with a Coefficient of Determination (COD, $R^{2}$ ) of 0.99997. The reported confidence intervals are standard error. The colors represent each of the six cycles, but the data fall very close together and cannot be distinguished, even with fine markers.

The measurement cycle is repeated three times and recorded, followed by an additional series of measurements made to higher temperatures (described below). The same process is performed to measure the room-temperature resistance after the higher-temperature measurements to verify the stability of the sensor and the soundness of the electrical connections. Figures 2 and 3 illustrate the data from the six measurement cycles on a typical sensor and show the errors attributed to voltage offset/bias. A linear fit is performed through the data, as plotted in Fig. 3, and the resistance is found from the slope (voltage/current), eliminating the effect of the voltage offset/bias. For this set of six measurements from one sensor, the room-temperature resistance was $9.199 \mathrm{ohm}$. The $R^{2}$ value for the concatenated fit through all six data sets was 0.99997. 
Figure 4 shows results from the same sensor, but with additional heating cycles extended to $50 \mathrm{~mA}$, to illustrate the resistance rise seen above $20 \mathrm{~mA}$, in air, due to self-heating. One can see that the resistance data presented in Fig. 2 and Fig. 4 provide no clear room-temperature resistance value, which is why the approach shown in Fig. 3 is preferable. At low currents (generally below $11 \mathrm{~mA}$ ), the offset/bias issue dominates the measurement, causing an error that shifts the measurement to lower values; the intercept is found to be $-3 \mathrm{mV}$, while it should be zero. Given that the applied voltages never exceeded $100 \mathrm{mV}$, this would be a substantial error if not found and corrected for.

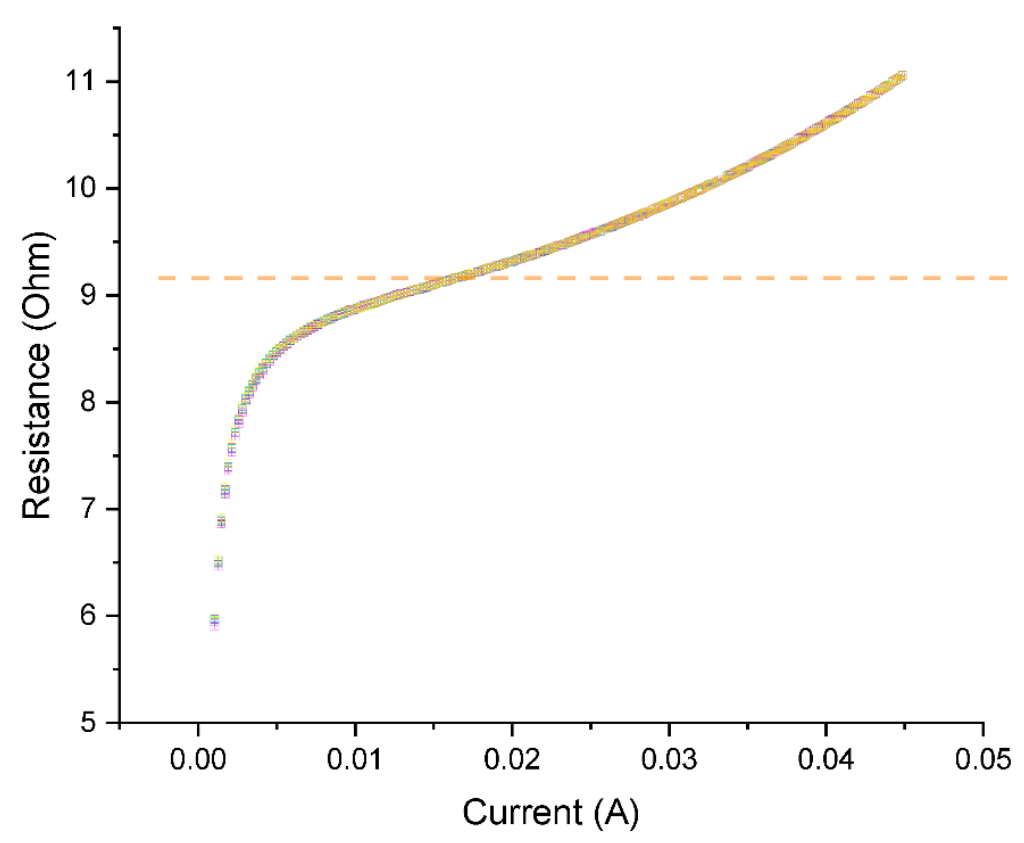

Fig. 4. Room-temperature resistance measurements from six measurement cycles on the same sensor as Fig. 2 and Fig. 3, but with the maximum current increased to $50 \mathrm{~mA}$ to demonstrate the self-heating effect and the erroneous rise in measured resistance at higher applied currents. The orange dashed line is the value derived from the slope of Fig. 3. The colors represent each of the six cycles, but the data fall very close together and cannot be distinguished, even with fine markers and lines.

As seen in Fig. 5, at currents above $20 \mathrm{~mA}$, self-heating causes the measured value to rise, resulting in an increase in the observed resistance; this is a real but unwanted effect. While unwanted, the measurement is not in error-the resistance is actually increasing as the sensor self-heats. To avoid this problem, we have to select conditions that avoid self-heating. These two effects create the appearance of a nonlinear relationship in Fig. 2, which was created to illustrate the possible measurement artifacts that can be introduced. Limiting the current and using the slope of the voltage-current plot as the best measure of resistance can solve both these measurement issues.

This work was done in general laboratory conditions, and the calibration curves were recorded in room air and at ambient humidity levels, which varied seasonally. The humidity levels were not controlled but are expected to have a small effect on the calibration curves. Doing all the calibrations and measurements in dry air is likely to reduce uncertainty, but we have not explored that aspect. 


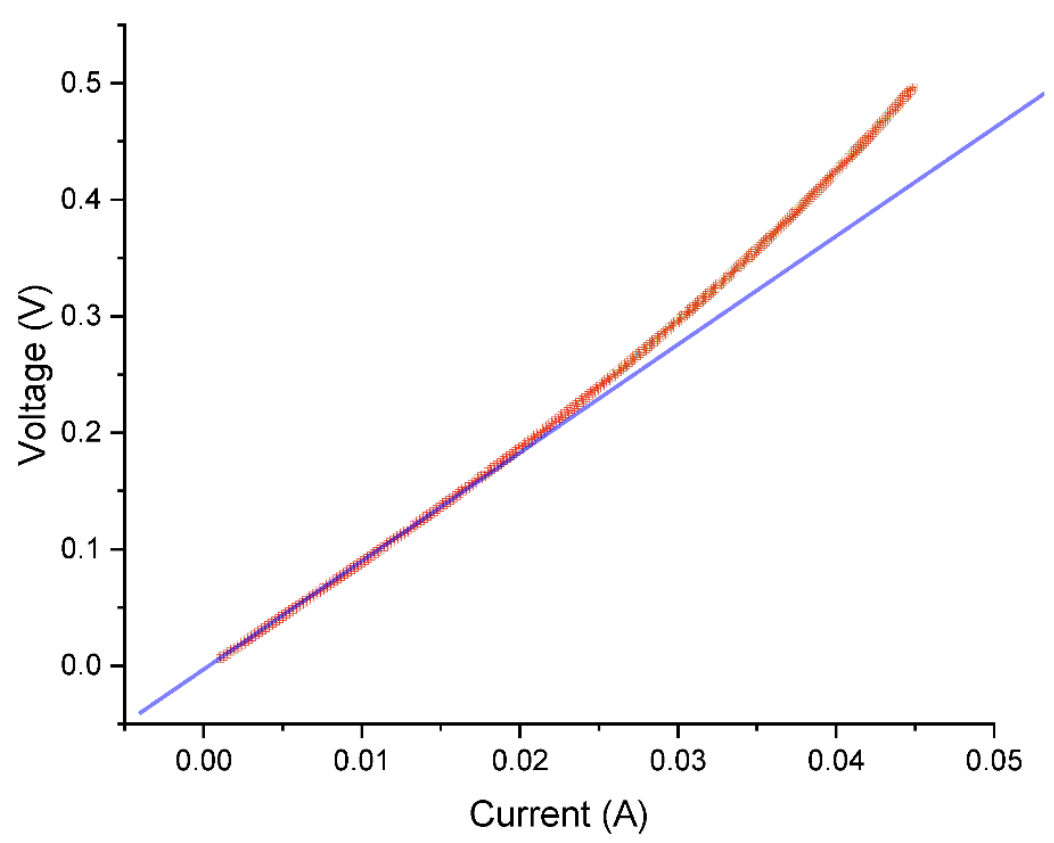

Fig. 5. The same data as Fig. 4, plotted as voltage vs. current, with the blue line representing the slope derived from the fit shown in Fig. 3. Self-heating is noticeable as the deviation from the linear fit from the data in Fig. 3.

\subsection{Elevated-Temperature Resistance Measurements}

After the room-temperature measurements, the resistance is measured during heating over the range $315^{\circ} \mathrm{C}$ to $690^{\circ} \mathrm{C}$. The same calibration software is used to apply current in steps to the sensors, and the temperature is measured using a fiber-optic pyrometer centered over the middle of the sensor. The temperature-dependent emissivity of the platinum was measured independently and reported in Ref. [8]; this emissivity can also be deduced from measurements of the melting temperatures of reference materials, and then scaling the emissivity to fit that data.

Figure 6 shows elevated-temperature resistance calibration measurements from two measurement cycles on each of 100 randomly selected sensors. As can be seen from the bimodal grouping of the results, a small subset of samples came from one production batch with an approximately $15 \%$ thinner layer of platinum, which results in higher resistance values. Of course, it is easy to note that all the sensors show individual variation, which we attribute to differences in film thickness across each wafer and from wafer to wafer. Such variations are expected in microfabrication. Figure 6 illustrates the importance of calibrating each individual sensor, as small changes in the process can produce dramatic changes in performance.

The data from each sensor are then used to create a calibration file that includes the room-temperature calibration results along with the elevated-temperature calibration results.

\section{Power Measurements as an Alternative Calibration}

Figure 7 shows the same data as were used to plot Fig. 6, but plotted as power vs. temperature, with the power calculated from the voltage drop across the active part of the sensor. Figure 8 through Fig. 10 are from the same data set and show increasing levels of detail. All the sensors (with $100 \mathrm{~nm}$ platinum and those with $85 \mathrm{~nm}$ platinum, as mentioned previously) follow the same power-temperature relationship, providing an alternative method to deduce the resistance-temperature curve, with slightly higher uncertainty than the pyrometer method. 


\section{Journal of Research of the National Institute of Standards and Technology}

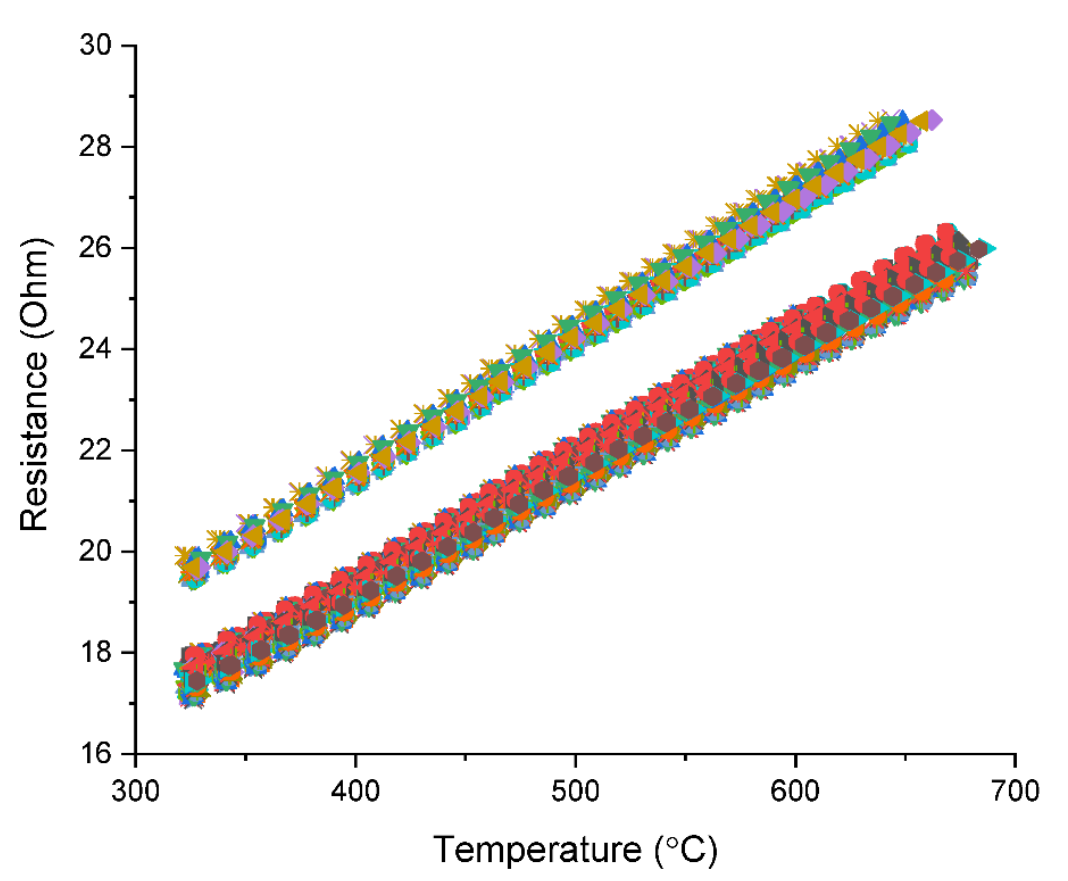

Fig. 6. Elevated-temperature calibration data for 100 randomly selected sensors. This data set falls into two groups, as one production batch had an inadvertently thinner layer of platinum, which resulted in approximately $15 \%$ higher resistance than our normal process. One should note that both the slope and intercept vary from sensor to sensor. The intention of this figure is to show the scatter in the data and the importance of calibrating each nanocalorimeter individually. We have not tried to fit all these data points to a single line or curve because the error would be dramatic.

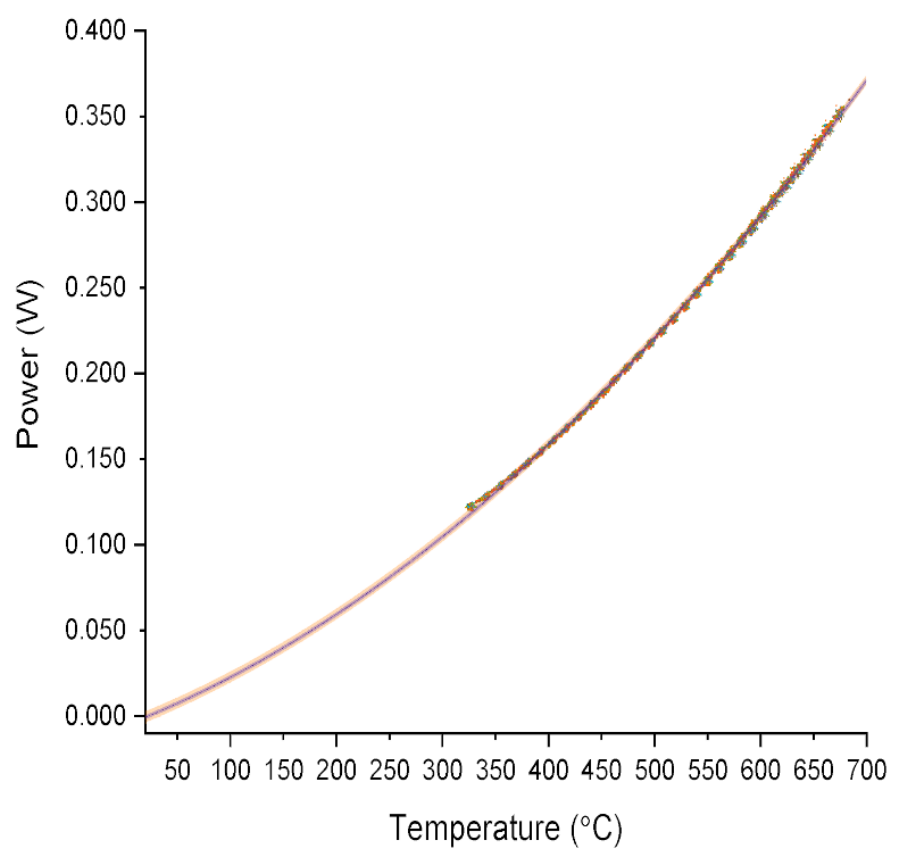

Fig. 7. Power as a function of temperature for the same 100 randomly selected sensors (approximately 6300 data points) shown in Fig. 6. The processing differences, seen as two separate groups on the resistance-temperature graphs, are not apparent in these power-temperature curves. The fit was constrained to room temperature at zero power. The orange band is the $95 \%$ confidence prediction interval. The colors represent each of the 100 randomly selected nanocalorimeter data sets, but the data fall very close together and cannot be distinguished, even with fine markers and lines. 


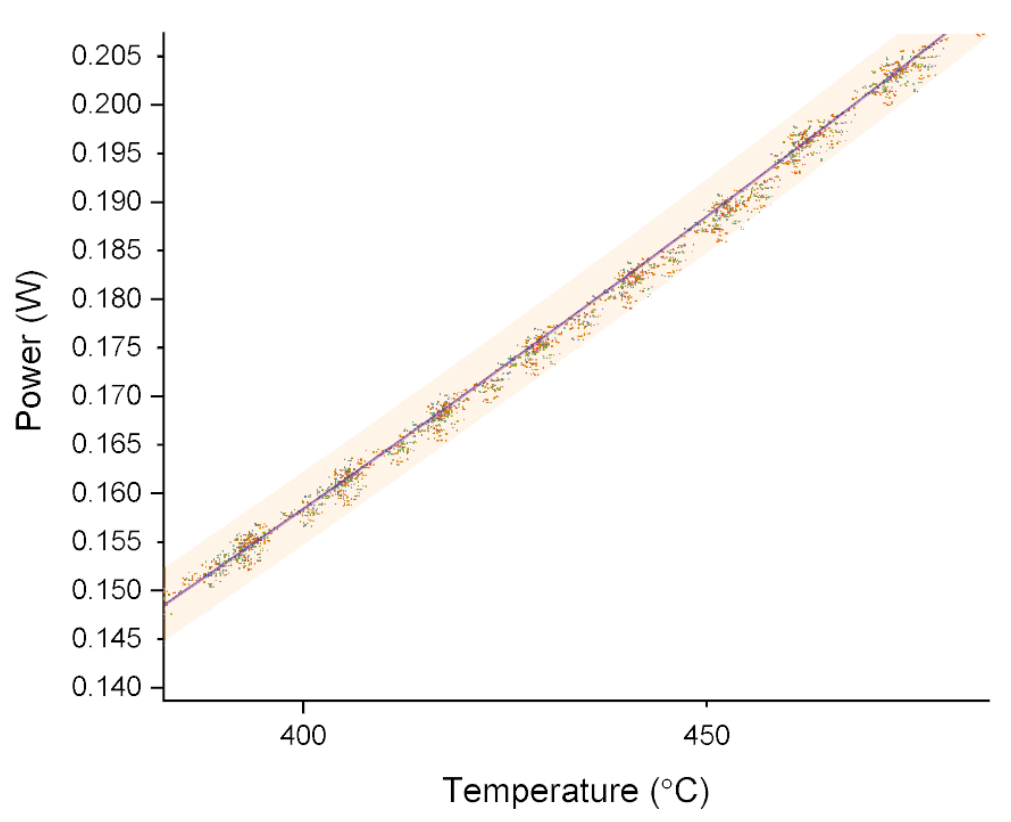

Fig. 8. More detailed view of the data in Fig. 7. The orange band is the $95 \%$ confidence prediction interval. The colors represent each of the 100 randomly selected nanocalorimeter data sets, but the data fall very close together and cannot be distinguished, even with fine markers and lines.

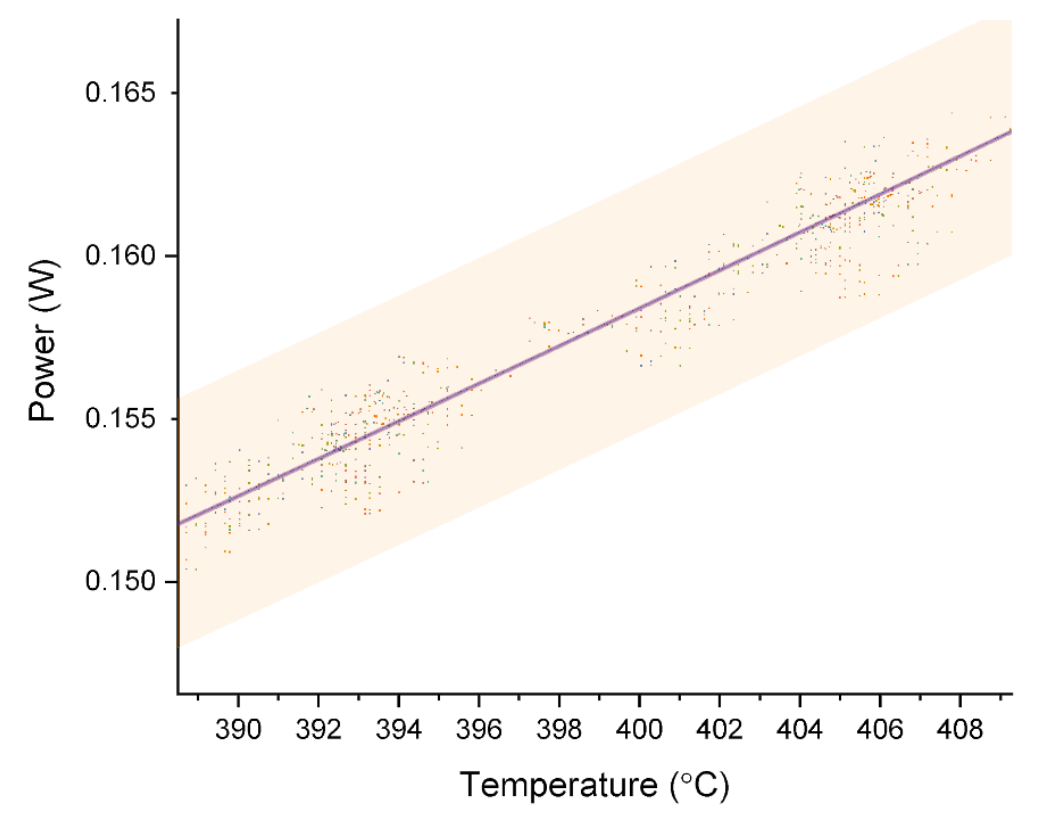

Fig. 9. More detailed view of the data in Fig. 8. The orange band is the $95 \%$ confidence prediction interval. The colors represent each of the 100 randomly selected nanocalorimeter data sets.

Knowing the power-temperature relationship, which would vary with the type of nanocalorimeter used, and the gas environment, allows one to heat each empty sensor, record the voltage and current, calculate the power and resistance, and then deduce the sensor temperature from the power data to generate a temperatureresistance calibration curve for each sensor.

In addition, Fig. 7 through Fig. 10 show that all 100 of the sensors we included fell along a well-defined curve. 


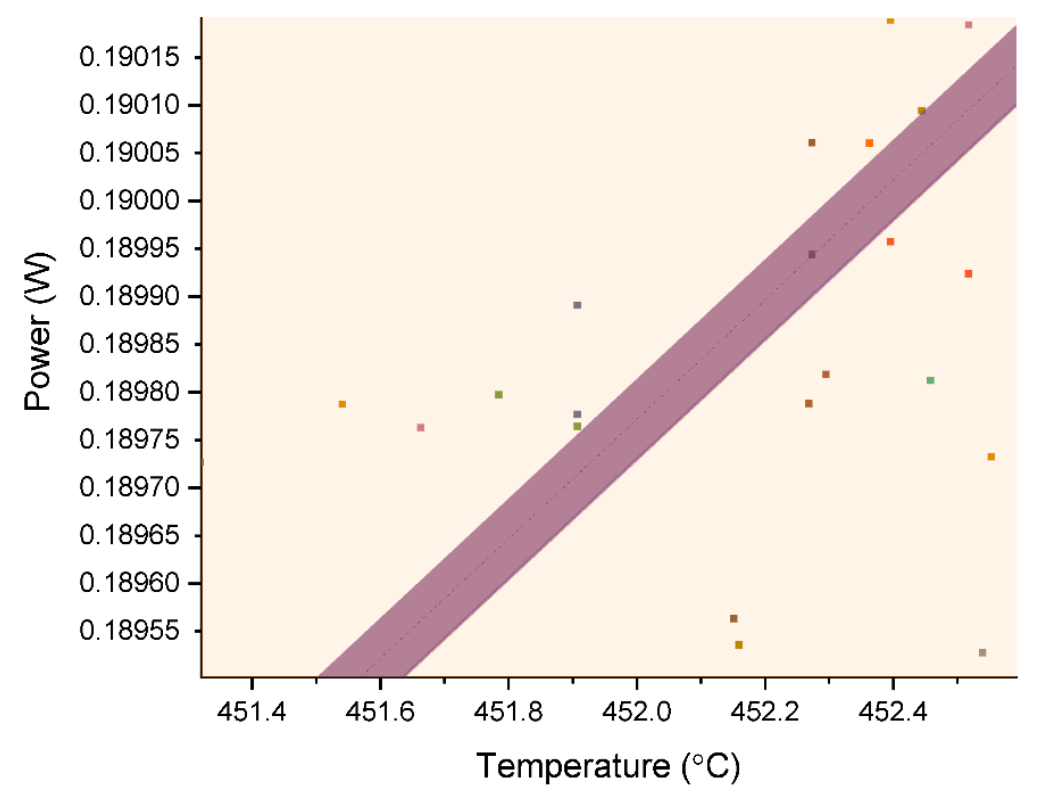

Fig. 10. More detailed view of the data in Fig. 9. The orange band (which fills the field of view) is the $95 \%$ confidence prediction interval. The $95 \%$ confidence interval of the fit is shown in the purple band; it is indistinguishable from the fit line in the other views. The colors represent each of the 100 randomly selected nanocalorimeter data sets, but the data fall very close together and cannot be distinguished, even with fine markers and lines.

This relationship can also be used as a type of "built-in self-test" (BIST) $[38,40]$ to verify the device was fabricated and calibrated correctly. Any points or sensors that do not fall on this line should be considered suspect and should be retested or investigated to understand the anomaly. The polynomial fit shown in Fig. 5 has an $R^{2}$ value of 0.99993 , with units of watts and degrees Celsius:

$$
\text { Power }=-5.68 \times 10^{-3}+2.3966 \times 10^{-4} \times T+4.2645 \times 10^{-7} \times T^{2} \text {. }
$$

Confidence intervals were calculated using Origin software. The definitions of the confidence intervals reported below are available at https://www.originlab.com/doc/Origin-Help/Fitted_Curve_Plot_Analysis. The $95 \%$ confidence interval for the fit reports the range of values for the best-fit line that define the $95 \%$ confidence interval. The $95 \%$ confidence interval for the prediction is the range where $95 \%$ of experimental data points are expected to fall. The $95 \%$ confidence interval of the fit is indistinguishable from the fit line in most views of this data set and is shown in a purple band that can be resolved only in Fig. 10. At $190 \mathrm{~mW}$, the $95 \%$ confidence interval of the fit is $452.30^{\circ} \mathrm{C}$ to $452.43^{\circ} \mathrm{C}$ ( or $\pm 0.065^{\circ} \mathrm{C}$ ).

The $95 \%$ confidence interval for the prediction is shown in the orange band and varies with power level. At $50 \mathrm{~mW}$, the $95 \%$ confidence prediction interval is $167^{\circ} \mathrm{C}$ to $186^{\circ} \mathrm{C}\left(\right.$ or $\left.\pm 9.5^{\circ} \mathrm{C}\right)$. At $150 \mathrm{~mW}$, the $95 \%$ confidence prediction interval is $379^{\circ} \mathrm{C}$ to $392^{\circ} \mathrm{C}$ ( or $\pm 6.5^{\circ} \mathrm{C}$ ). At $250 \mathrm{~mW}$, the $95 \%$ confidence prediction interval is $537{ }^{\circ} \mathrm{C}$ to $548{ }^{\circ} \mathrm{C}$ ( or $\pm 5.5^{\circ} \mathrm{C}$ ). At $350 \mathrm{~mW}$, the $95 \%$ confidence prediction interval is $670{ }^{\circ} \mathrm{C}$ to $679^{\circ} \mathrm{C}\left(\right.$ or $\left.\pm 4.5^{\circ} \mathrm{C}\right)$.

\section{Calibration}

\subsection{Virtual Instrument}

Calibration is performed on a special-built instrument, with an automated process run through a LabVIEW virtual instrument (VI). The VI was written at NIST for the Nanocalorimetry Measurements Project. Upon starting the VI, the user creates or edits a calibration recipe, as shown in Fig. 11. A typical recipe, with three cycles to measure the room-temperature resistance, three heating cycles, and three more cycles to confirm the room-temperature resistance, is shown. As can be seen in Fig. 12, the user enters the type of measurement, the 
number of repetitions, the minimum voltage, the maximum voltage, the voltage step, and the number of measurements per step. The VI calculates the estimated duration based on the entered information. Figure 13 shows the VI after running an experiment.

Each sensor is given a unique identifier (ID), which is entered along with the operator ID. The fiber-optic pyrometer is aligned for each measurement, following the steps outlined below. The VI applies the voltage to the sensor and measures the current in the measurement loop and the voltage across the voltage pads on the sensor. A second VI, shown in Fig. 14, is used to calculate the TCR, which is saved into a data file to be used by the VI that controls the nanocalorimeter experiments. A paper log is also maintained as a redundant record with the sample ID and calibration coefficients. The detailed steps of the calibration procedure are included in the supplemental information available online.

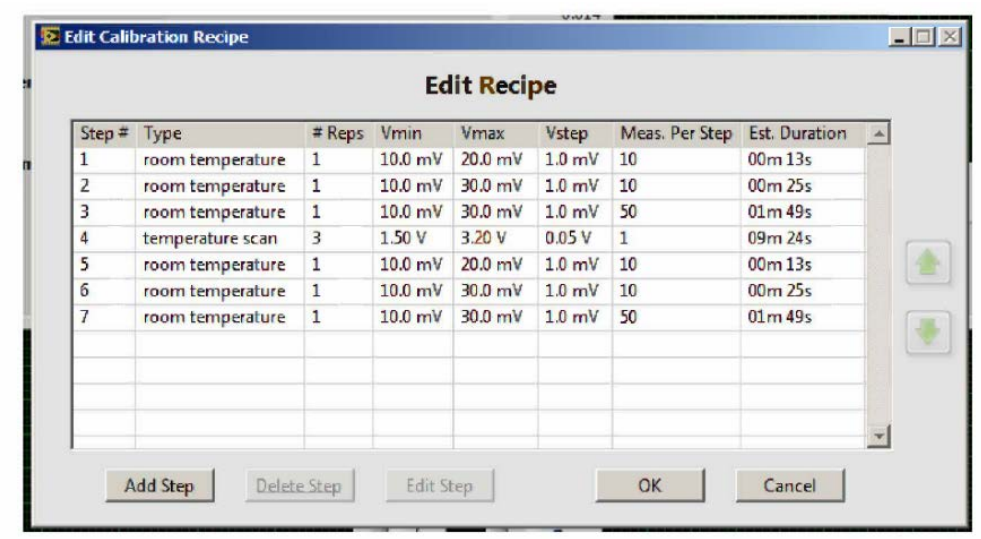

Fig. 11. A screen capture of the "Edit Recipe" window showing an example recipe used to calibrate the nanocalorimeter sensors. This recipe produces three "before" room-temperature measurements, three up-and-down temperature ramps, and three "after" roomtemperature measurements.

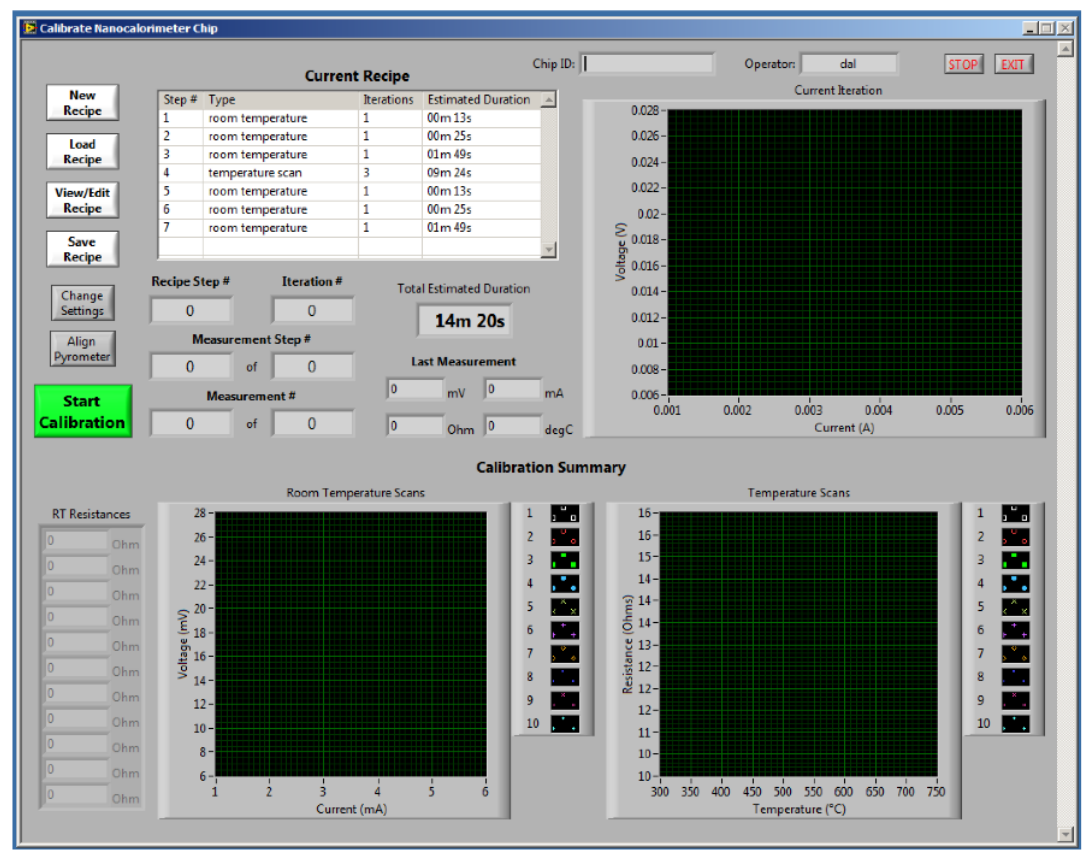

Fig. 12. Screen capture of the main VI for nanocalorimeter sensor calibration, before starting a calibration. The recipe is shown in the upper left, and the data will populate the other windows as they are collected. The software predicts the calibration measurements and heating/cooling cycles for this recipe will take $14 \mathrm{~min}$ and $20 \mathrm{~s}$. 


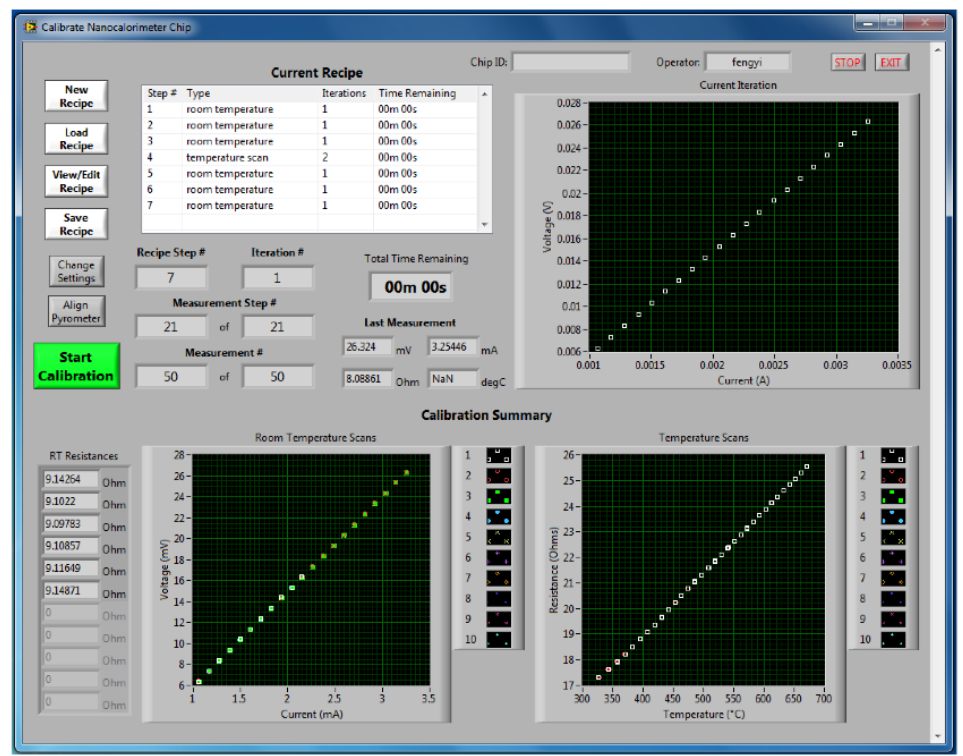

Fig. 13. Screen capture of the main VI for nanocalorimeter sensor calibration, after running the measurements for a calibration.

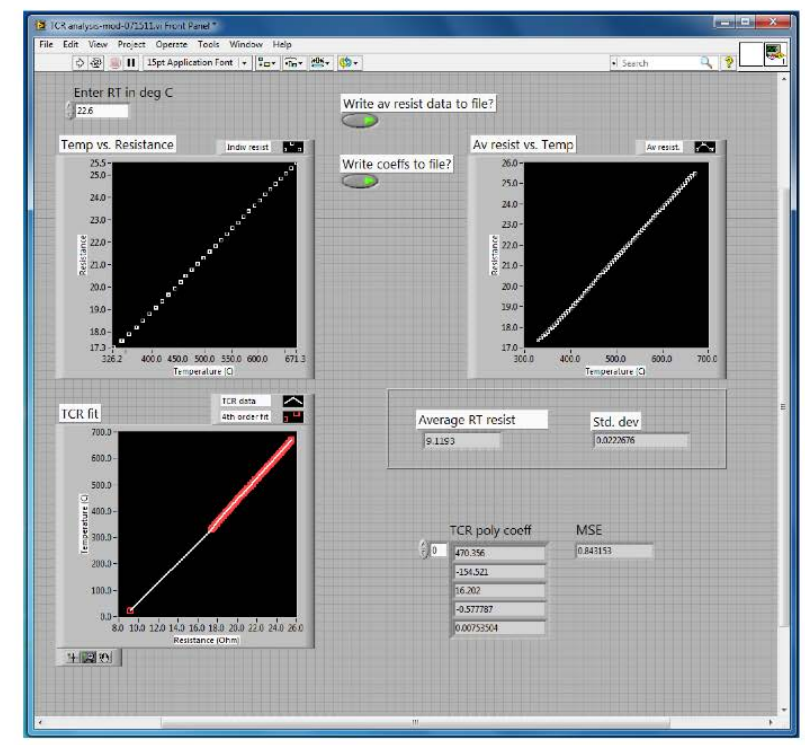

Fig. 14. Screen capture of the VI used to calculate the TCR values, based on the calibration recipe and data acquired as shown in Fig. 13. This VI imports the six room-temperature resistance scans and the three heating and cooling scans and fits them to a fourth-order polynomial used for the TCR. Other fits can be selected as well.

\subsection{Calibration Extrapolation}

This calibration strategy is valid for measurements within the range of the temperature measurements made (approximately room temperature to $700^{\circ} \mathrm{C}$ ). We have successfully made measurements using these sensors to $1200{ }^{\circ} \mathrm{C}$, but that requires either increasing the calibration range or extrapolating the calibration values to temperatures outside the range of measurement, something that will rapidly expand the measurement uncertainty. As an example, Figs. 15 and 16 illustrate efforts to extrapolate the calibration outside the measurement range. In Fig. 15, each fit is plotted with and without inclusion of the room-temperature resistance value as a constraint. Some of the fits fail dramatically. 
The experimentally determined melting point for gold is shown in Fig. 16, along with two fits that worked better and do not "blow up" outside the measurement range. Figure 16 shows a linear fit and a second-order polynomial fit, both including the room-temperature constraint. They are off by $96{ }^{\circ} \mathrm{C}$ and $62{ }^{\circ} \mathrm{C}$, respectively, evaluated at the resistance recorded at the top of the melting peak (32.87 $\Omega$, corresponding to a nominal temperature of $1064.18^{\circ} \mathrm{C}$ ), which was measured in air.

Figure 17 shows the extrapolation of the power-temperature curve to the melting point of the same gold thin film sample. The difference between the nominal peak melting temperature and the temperature derived from the curve fit is $10^{\circ} \mathrm{C}$, which is much better than the error due to extrapolating the resistance-temperature curve. These values are enumerated to illustrate the comparison and are not meant to quantify the uncertainty.

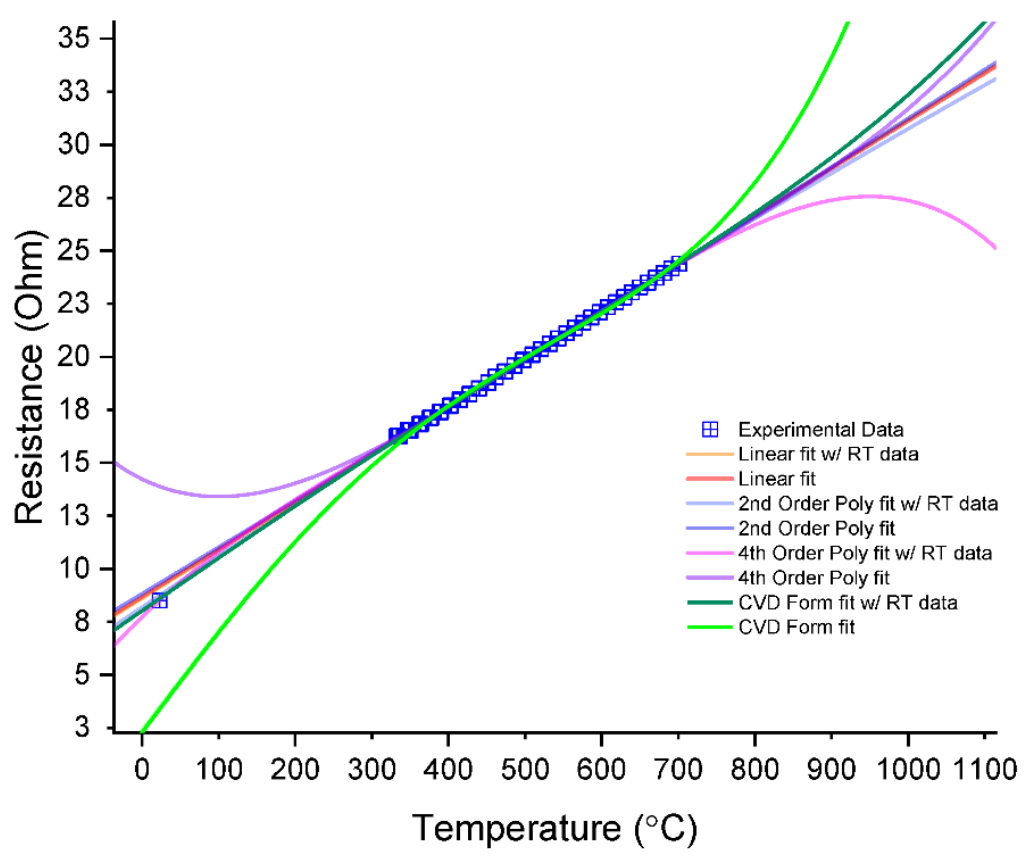

Fig. 15. Various fits through the calibration measurements (blue squares) that could potentially be used to extrapolate the calibration data to higher temperatures. The graph shows linear, $2^{\text {nd }}$ order polynomial, $4^{\text {th }}$ order polynomial and a fit following the form of the CallendarVan Dusen (CVD) equation. The divergences seen with some fits outside the data range clearly illustrates the hazard in choosing a method to extrapolate calibrations outside the measured range. For each, the fits were performed including the room-temperature (RT) data (pink, dark green, light orange, light blue) or ignoring the room-temperature data (light green, purple, dark blue, dark orange). 


\section{Journal of Research of the National Institute of Standards and Technology}

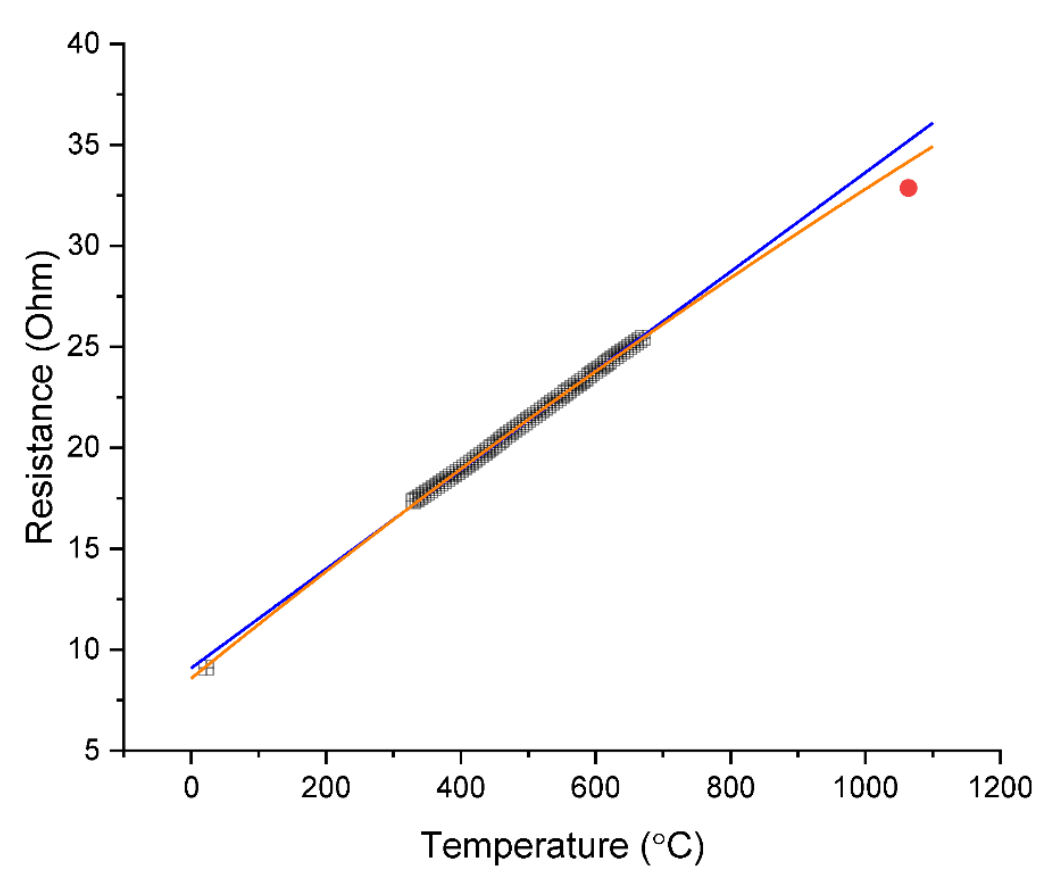

Fig. 16. Diagram showing the linear (blue line, $R^{2}=0.9992$ ) and second-order polynomial (orange line, $R^{2}=0.9998$ ) fits from Fig. 15 , extrapolated to higher temperatures, along with an experimentally measured (peak) value for the melting of gold (red dot, nominal 1064.18 ${ }^{\circ} \mathrm{C}$ and measured $32.87 \Omega$ ) as an example of a known melting peak at higher temperatures. The second-order polynomial fit extrapolates to $1002{ }^{\circ} \mathrm{C}$ at $32.87 \Omega$, and the linear fit extrapolates to $968^{\circ} \mathrm{C}$ at $32.87 \Omega$; compared to the nominal melting temperature of the gold thin film, the extrapolated fits are $62{ }^{\circ} \mathrm{C}$ to $96^{\circ} \mathrm{C}$ too low. This example is given for information and is not intended as a quantification of uncertainty. These fits included the room-temperature data.

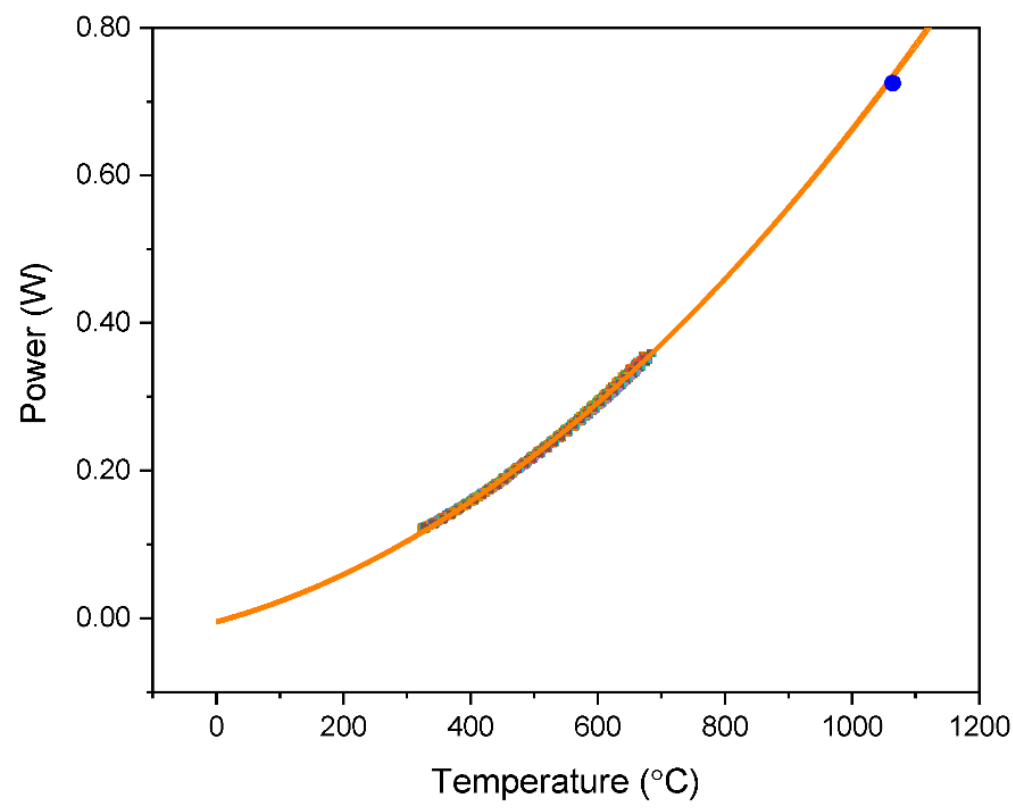

Fig. 17. The same data and second-order polynomial from Fig. 7, extrapolated to higher temperatures, as another potential strategy to extrapolate the calibration to higher temperatures. The orange line is the fit. An experimentally determined point (blue dot) for the melting peak of a $65 \mathrm{~nm}$ layer of gold (nominal $1064.18{ }^{\circ} \mathrm{C}$ and measured $724.9 \mathrm{~mW}$ ) is shown as an example of the error from extrapolating the power-temperature curve-it is off by $10^{\circ} \mathrm{C}$ at $1064{ }^{\circ} \mathrm{C}$. This example is given for information and is not intended as a quantification of uncertainty. As in Fig. 7 and Fig. 16, the curve fit was constrained to pass through zero power at room temperature. 


\section{Discussion}

This article summarizes the design and calibration of NIST nanocalorimeter sensors and presents calibration data and analysis from 100 randomly selected sensor chips. Calibration using a pyrometer, with the temperatures verified against melting point standards, remains our best calibration strategy.

Extrapolating resistance-temperature values to higher temperatures greatly increases the measurement uncertainty. The power-temperature relationship can provide reasonable calibrations, without needing expensive equipment, and offers uncertainties ( $95 \%$ confidence interval for the prediction) that range from 5 ${ }^{\circ} \mathrm{C}$ to $10^{\circ} \mathrm{C}$, depending on the measurement temperature, and it provides a means to extrapolate the calibration to higher temperatures without dramatically changing the measurement uncertainty.

\section{Appendix-Detailed Fabrication and Calibration Procedures}

The general strategy for the fabrication of the nanocalorimeters is to start with standard $100 \mathrm{~mm}$ (4 inch nominal) wafers, clean them thoroughly, grow $100 \mathrm{~nm}$ of low-stress silicon nitride on the front and back, pattern the platinum heater/temperature sensor on the front, use reactive ion etching to open windows in the silicon nitride on the back, and then use potassium hydroxide (KOH) to deep etch from the back, through the silicon wafer, stopping at the front-side silicon nitride layer, followed by dicing, annealing, and calibration.

\subsection{Detailed Fabrication Process Developed for the CNST Cleanroom at NIST}

9.1.1 This process requires two 5 inch $(12.7 \mathrm{~cm})$ chrome-on-glass masks—one for the front-side and one for the back-side patterns. The masks were produced in AutoCAD and saved in data exchange format (DXF). The masks were written using a Heidelberg DWL 2000 mask writer. Links to the DXF files are listed in supplemental materials.

9.1.2 The silicon wafers are P/Bo doped, 1-10 ohm-cm, $100 \mathrm{~mm}$ (4 in. nominal) double-side polished, $<100>$ orientation, nominally $525 \mu \mathrm{m}$ thick (the specification is given as a range of $500 \mu \mathrm{m}$ to $550 \mu \mathrm{m})$.

9.1.3 All reagents used are microelectronics grade. All water used is deionized to cleanroom specifications.

9.1.4 RCA clean

9.1.4.1 Standard Clean (SC) 1 (SC1) $\left(5: 1: 1 \mathrm{H}_{2} \mathrm{O}: \mathrm{NH}_{4} \mathrm{OH}: \mathrm{H}_{2} \mathrm{O}_{2}\right.$ at $\left.80^{\circ} \mathrm{C}\right)$ for $10 \mathrm{~min}$

9.1.4.2 Dump rinse

9.1.4.3 1\% HF for $1 \mathrm{~min}$

9.1.4.4 Dump rinse

9.1.4.5 SC2 (5:1:1 $\mathrm{H}_{2} \mathrm{O}: \mathrm{HCl}: \mathrm{H}_{2} \mathrm{O}_{2}$ at $\left.80{ }^{\circ} \mathrm{C}\right)$ for $10 \mathrm{~min}$

9.1.4.6 Dump rinse

9.1.4.7 Spin rinse dry (SRD)

9.1.5 Silicon nitride deposition (front and back) $\mathrm{SiN}_{x}$

9.1.5.1 Deposition is by Low Pressure Chemical Vapor Deposition (LPCVD) furnace/bank 3_silicon nitride

9.1.5.2 Low-stress recipe (LSTSIN.010)

9.1.5.3 Nominal $100 \mathrm{~nm}$ thickness

9.1.5.4 Calculate deposition time based on posted deposition rate (typical rate is $5.85 \mathrm{~nm} / \mathrm{min}$ )

9.1.5.5 Measure and record thickness using J. A. Woollam M-2000 DI Spectroscopic Ellipsometer

9.1.6 Frontside metal patterning by lift-off process

9.1.6.1 Photolithography step

9.1.6.1.1. Hexamethyldisilazane (HMDS) prime (vapor prime at $150{ }^{\circ} \mathrm{C}$ )

9.1.6.1.2. Spin 1 (LOR-3A photoresist, target 400 nm thickness)

9.1.6.1.2.1. $500 \mathrm{rpm}, 5.0 \mathrm{~s}$

9.1.6.1.2.2. $3000 \mathrm{rpm}, 60.0 \mathrm{~s}$

9.1.6.1.2.3. Bake at $200{ }^{\circ} \mathrm{C}$ for $5 \mathrm{~min}$

9.1.6.1.2.4. Cool for $5 \mathrm{~min}$ 
9.1.6.1.3. Spin 2 (S-1813 photoresist, target $1.3 \mu \mathrm{m})$

9.1.6.1.3.1. $500 \mathrm{rpm}, 5.0 \mathrm{~s}$

9.1.6.1.3.2. $4000 \mathrm{rpm}, 45.0 \mathrm{~s}$

9.1.6.1.3.3. Bake at $115^{\circ} \mathrm{C}$ for $1 \mathrm{~min}$

9.1.6.1.3.4. Cool for $1 \mathrm{~min}$

9.1.6.1.4. Expose (Suss MA6/BA6 mask aligner)

9.1.6.1.4.1. Frontside metal mask

9.1.6.1.4.2. Calculate and use exposure time based on lamp intensity (target dose $120 \mathrm{~mJ} / \mathrm{cm}^{2}$ )

9.1.6.1.5. Develop

9.1.6.1.5.1. MF-319, $1 \mathrm{~min}$ (or until features are clear)

9.1.6.1.5.2. Rinse with $\mathrm{H}_{2} \mathrm{O}$

9.1.6.1.5.3. Blow dry

9.1.6.1.6. Oxygen plasma descum

9.1.6.1.6.1. Unaxis Reactive Ion Etch (RIE) \#1

9.1.6.1.6.2. Recipe: G_DESCUM.PRC (target $75 \mathrm{~nm} / \mathrm{min}$ ), $1 \mathrm{~min}$

9.1.7 Metal deposition step

9.1.7.1 E-beam evaporation (E-beam 1 or 2$)$

9.1.7.1.1. Nominal $10 \mathrm{~nm}$ Ta at $1 \AA \AA$ /s (typically $100 \mathrm{~s}$ )

9.1.7.1.2. Nominal $100 \mathrm{~nm}$ Pt at $1 \AA$ /s (typically $1000 \mathrm{~s}$ )

9.1.8 Lift-off step

9.1.9 Remover PG at $80^{\circ} \mathrm{C}$ for $\approx 15 \mathrm{~min}$ (Remover PG is a proprietary composition that includes hexamethyldisilazane).

9.1.10 Rinse

9.1.10.1 Isopropyl alcohol (IPA) for $3 \mathrm{~min}$

9.1.10.2 Water for $3 \mathrm{~min}$

9.1.11 Spin rinse dry

9.1.12 Protect front side with photoresist (more experienced users may omit)

9.1.12.1 HMDS prime

9.1.12.2 Spin 1 (photoresist S-1813, nominal $1.3 \mu \mathrm{m}$ )

9.1.12.3 $500 \mathrm{rpm}, 5.0 \mathrm{~s}$

9.1.12.4 $4000 \mathrm{rpm}, 45.0 \mathrm{~s}$

9.1.12.5 Bake at $115^{\circ} \mathrm{C}$ for $1 \mathrm{~min}$

9.1.12.6 Cool for $1 \mathrm{~min}$

9.1.13 Backside nitride patterning

9.1.13.1 Photolithography step

9.1.13.1.1. HMDS prime

9.1.13.1.2. $\quad$ Spin 1 (photoresist S-1813, nominal $1.3 \mu \mathrm{m}$ )

9.1.13.1.2.1. $500 \mathrm{rpm}, 5.0 \mathrm{~s}$

9.1.13.1.2.2. $4000 \mathrm{rpm}, 45.0 \mathrm{~s}$

9.1.13.1.2.3. Bake at $115^{\circ} \mathrm{C}$ for $1 \mathrm{~min}$

9.1.13.1.2.4. Cool for $1 \mathrm{~min}$

9.1.13.1.3. Expose back side (Suss MA6/BA6 aligner)

9.1.13.1.3.1. Back-side nitride mask

9.1.13.1.3.2. Align with existing pattern

9.1.13.1.3.3. Calculate exposure time based on lamp intensity (target $120 \mathrm{~mJ} / \mathrm{cm}^{2}$ )

9.1.13.1.4. Develop

9.1.13.1.4.1. MF-319, 1 min (or until features are clear). (MF-319 is a proprietary composition that includes water and tetramethylammonium hydroxide).

9.1.13.1.4.2. Rinse with deionized water

9.1.13.1.4.3. Blow dry

9.1.13.2 RIE $\mathrm{CHF}_{3}$ etch (Unaxis RIE \#1)

9.1.13.2.1. Recipe "SI3N4NEW.PRC," nominal etch rate $20 \mathrm{~nm} / \mathrm{min}$ 


\subsection{Calculate etch time based on expected nitride thickness with $10 \%$ overetch time \\ 9.1.13.2.3. Typical etch time is: $100 \mathrm{~nm} \div 20 \mathrm{~nm} / \mathrm{min} \times 1.1=5.5 \mathrm{~min}$}

9.1.13.3 Oxygen plasma cleaning (to remove rest of photoresist, may require both sides)

9.1.13.4 Unaxis RIE \#1

9.1.13.5 Recipe: Cleaning.PRC

9.1.13.6 $15 \mathrm{~min}$

9.1.13.7 (Note: Solvent strip with remover PG is an acceptable alternative)

9.1.14 Back-side deep silicon $\mathrm{KOH}$ etch

(Note: The wafer is very fragile during and after this step)

(Note: Always insert wafer into liquids on edge)

9.1.14.1 $30 \% \mathrm{KOH}$ (premixed bath), $90^{\circ} \mathrm{C}$

9.1.14.1.1. (Note: Do not use old KOH baths to avoid metal contamination and photoresist residue left over from other users)

9.1.14.2 Clamp wafer in protective holder (Advanced MicroMachining Tools, Single 4) and place in protective wafer carrier- do not use photoresist as a $\mathrm{KOH}$ etch mask because it is not sufficient AND will contaminate the bath

\subsubsection{No agitation}

9.1.14.4 Nominal rate is $2.25 \mu \mathrm{m} / \mathrm{min}$ for $30 \% \mathrm{KOH}$ at $90{ }^{\circ} \mathrm{C}$

9.1.14.5 Nominal etch time: 230 min (it will not be this exactly—check, and continue until features are clear)

9.1.14.6 Avoid over etching

9.1.14.7 Acid dip (note: Do not let $\mathrm{KOH}$ residue dry)

9.1.14.8 Rinse with wafer still in holder:

9.1.14.8.1. Warm water for $1 \mathrm{~min}$

9.1.14.8.2. Over flow water for $5 \mathrm{~min}$

9.1.14.8.3. Water dunk (membranes up)

9.1.14.8.4. Gentle dry with wipe around edge of holder

\subsubsection{Remove wafer from holder}

9.1.15 Cleave by hand into individual die with a diamond scribe (note: other users have reported using photoresist to attach the wafer to a handle wafer and using a die saw to separate the die; the membranes will not survive the vacuum chuck on the die saw without some approach like this; we choose just to cleave by hand)

9.1.16 Anneal

\subsection{Calibration Procedure}

9.2.1 Turn on the instruments and let them warm up for at least half an hour to stabilize if they were turned off

9.2.1.1 OPTITHERM III Pyrometer

9.2.1.2 National Instruments PXI Chassis and PXI Sourcemeter PXI-1033

9.2.1.3 Dell personal computer (PC)

9.2.1.4 Water circulator (if being used to stabilize room temperature)

9.2.2 Load two nanocalorimeter sensors in the aluminum holder and secure the top of the holder with four screws; the electrical connections are made with spring pins in the top of the holder

9.2.3 On the PC, open the LabVIEW calibration VI "Calibrate Nanocalorimeter Chip.vi"

9.2.3.1 Enter user ID

9.2.4 Confirm settings within the VI

9.2.4.1 Source Measure Unit (SMU) location = PXI1Slot2 (this would vary by instrument)

9.2.4.2 Sensor type $=$ remote

9.2.4.3 Pyrometer port $=$ COM7 
9.2.4.4 Current limit $=300 \mathrm{~mA}$

9.2.4.5 Ambient temperature $=23^{\circ} \mathrm{C}$

9.2.5 Create or load a saved recipe (an example is given in Fig. 6)

9.2.6 Turn the screw on the manual stage to move the pyrometer head forward and above the sensor to be calibrated

9.2.7 Align the pyrometer

9.2.7.1 Enable SMU

9.2.7.2 Enable pyrometer

9.2.7.3 Increase voltage to $1.8 \mathrm{~V}$ (a typical value), so the sensor heats enough to generate a signal on the pyrometer

9.2.7.4 Move the pyrometer head in forward and backward to find the maximum reported temperature value (which is taken to be the center)

9.2.7.5 Set the voltage range for the calibration

9.2.7.5.1. In the VI, decrease the applied voltage to find the minimum voltage where the pyrometer can make a measurement (about $1.45 \mathrm{~V}$, which corresponds to a temperature of about $320^{\circ} \mathrm{C}$ on this sensor)

9.2.7.5.2. Disable SMU and pyrometer

9.2.7.5.3. Set the minimum voltage for a sweep to the minimum plus $0.01 \mathrm{~V}(1.50 \mathrm{~V}$ is common)

9.2.7.5.4. Set the maximum voltage based on the temperature range over which you wish to calibrate (3.1 volts at the SMU is common, with roughly 1.5 volts differential across the sensor and a maximum temperature of $675^{\circ} \mathrm{C}$ )

9.2.8 Calibration

9.2.8.1 Start calibration by clicking on the "start calibration" button

9.2.8.2 Enter a calibration file name and location

9.2.8.3 Enter the results in the paper $\log$ as a redundant record

9.2.8.4 When completed, calibrate the second sensor if desired

9.2.8.4.1. Shift the pyrometer to the second sensor location

9.2.8.4.2. Turn the sensor switch to the other sensor

9.2.8.4.3. Enter the new sensor ID

9.2.8.4.4. Repeat the procedure from the alignment step (see Sec. 8.2.7)

9.2.8.4.5. Move the pyrometer head out of the way and unload the samples, storing them in numbered locations

9.2.9 Click the "exit" button to close the VI

9.2.10 Calculate the TCR values

9.2.10.1 Open the VI "TCR analysis-mod-071511.vi”

9.2.10.2 Select each of the data files to use in the analysis and click "cancel” to return to the VI

9.2.10.3 Run the VI to calculate the TCR values

9.2.10.4 Examine the fit and reported uncertainties as a quality check

9.2.10.5 Save the results as a “.tcr" file format

9.2.10.6 Record the TCR values in the paper log

9.2.10.7 Exit

\section{Supplemental Materials}

- DOI: https://doi.org/10.18434/M32113

o AutoCAD drawing files for the front and back 5 inch $(12.7 \mathrm{~cm})$ masks needed to pattern $100 \mathrm{~mm}$ (4 inch $[10.1 \mathrm{~cm}]$ ) wafers. Files are in both AutoCAD DWG format and DXF format. The drawing for the back-side mask has been mirrored as is appropriate for lithography using a contact aligner.

- $\quad$ DOI: https://doi.org/10.18434/M32114

o 3D solid model of a single nanocalorimeter as a Solidworks assembly drawing, with individual layers as Solidworks part drawings. 
- DOI: https://doi.org/10.18434/M32117

- Compressed archive of LabVIEW VIs for calibration and TCR calculation.

- DOI: https://doi.org/10.18434/M32115

○ Calibration data for room-temperature measurements shown in Fig. 2 through Fig 5.

- Calibration data for elevated-temperature measurements on 100 randomly selected nanocalorimeters shown in Fig. 6 through Fig. 10.

\section{References}

[1] Arlington SQ, Yi F, LaVan DA, Weihs TP (2019) A nanocalorimetric study of the effect of composition gradients on crystallization in amorphous Cu-Zr thin films. AIP Advances 9(3). https://doi.org/10.1063/1.5080312

[2] DeLisio JB, Yi F, LaVan DA, Zachariah MR (2017) High heating rate reaction dynamics of Al/CuO nanolaminates by nanocalorimetry-coupled time-of-flight mass spectrometry. Journal of Physical Chemistry C 121(5):2771-2777. https://doi.org/10.1021/acs.jpcc.6b11114

[3] Franke E, LaVan DA, Volkert CA (2018) Quantifying DC differential scanning nanocalorimetry for determining heat capacities. Thermochimica Acta 668:116-125. https://doi.org/10.1016/j.tca.2018.08.006

[4] Grapes MD, LaGrange T, Friedman LH, Reed BW, Campbell GH, Weihs TP, LaVan DA (2014) Combining nanocalorimetry and dynamic transmission electron microscopy for in situ characterization of materials processes under rapid heating and cooling. Review of Scientific Instruments 85(8): 084902-084901 to 084902-084912. https://doi.org/10.1063/1.4892537

[5] Grapes MD, LaGrange T, Woll K, Reed BW, Campbell GH, LaVan DA, Weihs TP (2014) In situ transmission electron microscopy investigation of the interfacial reaction between $\mathrm{Ni}$ and $\mathrm{Al}$ during rapid heating in a nanocalorimeter. APL Materials 2(11). https://doi.org/10.1063/1.4900818

[6] Grapes MD, Santala MK, Campbell GH, LaVan DA, Weihs TP (2017) A detailed study of the Al3Ni formation reaction using nanocalorimetry. Thermochimica Acta 658:72-83. https://doi.org/10.1016/j.tca.2017.10.018

[7] Kummamuru RK, De La Rama L, Hu L, Vaudin MD, Efremov MY, Green ML, LaVan DA, Allen LH (2009) Measurement of heat capacity and enthalpy of formation of nickel silicide using nanocalorimetry. Applied Physics Letters 95(18). https://doi.org/10.1063/1.3255009

[8] Swaminathan P, Burke BG, Holness AE, Wilthan B, Hanssen L, Weihs TP, LaVan DA (2011) Optical calibration for nanocalorimeter measurements. Thermochimica Acta 522(1-2):60-65. https://doi.org/10.1016/j.tca.2011.03.006

[9] Swaminathan P, Grapes MD, Woll K, Barron SC, LaVan DA, Weihs TP (2013) Studying exothermic reactions in the Ni-Al system at rapid heating rates using a nanocalorimeter. Journal of Applied Physics 113(14). https://doi.org/10.1063/1.4799628

[10] Swaminathan P, LaVan DA, Weihs TP (2011) Dynamics of solidification in Al thin films measured using a nanocalorimeter. Journal of Applied Physics 110(11). https://doi.org/10.1063/1.3668128

[11] Yi F, DeLisio JB, Nguyen N, Zachariah MR, LaVan DA (2017) High heating rate decomposition dynamics of copper oxide by nanocalorimetry-coupled time-of-flight mass spectrometry. Chemical Physics Letters 689:26-29. https://doi.org/10.1016/j.cplett.2017.09.066

[12] Yi F, DeLisio JB, Zachariah MR, LaVan DA (2015) Nanocalorimetry-coupled time-of-flight mass spectrometry: identifying evolved species during high-rate thermal measurements. Analytical Chemistry 87(19):9740-9744. https://doi.org/10.1021/acs.analchem.5b01872

[13] Yi F, Kim IK, Li S, LaVan DA (2014) Hydrated/dehydrated lipid phase transitions measured using nanocalorimetry. Journal of Pharmaceutical Sciences 103(11):3442-3447. https://doi.org/10.1002/jps.24187

[14] Yi F , LaVan DA (2013) Electrospray-assisted nanocalorimetry measurements. Thermochimica Acta 569:1-7. https://doi.org/10.1016/j.tca.2013.06.015

[15] Yi F, Osborn W, Betz J, LaVan DA (2015) Interactions of adhesion materials and annealing environment on resistance and stability of MEMS platinum heaters and temperature sensors. Journal of Microelectromechanical Systems 24(4):1185-1192. https://doi.org/10.1109/Jmems.2015.2394483

[16] Yi F, Stevanovic A, Osborn WA, Kolmakov A, LaVan DA (2017) A multi-environment nanocalorimeter with electrical contacts for use in a scanning electron microscope. Materials Horizons 4(6):1128-1134. https://doi.org/10.1039/c7mh00513j

[17] de la Rama LP, Hu L, Ye ZC, Efremov MY, Allen LH (2013) Size effect and odd-even alternation in the melting of single and stacked AgSCn layers: synthesis and nanocalorimetry measurements. Journal of the American Chemical Society 135(38):1428614298. https://doi.org/10.1021/ja4059958

[18] Efremov MY, Olson EA, Zhang M, Allen LH (2003) Glass transition of thin films of poly(2-vinyl pyridine) and poly(methyl methacrylate): nanocalorimetry measurements. Thermochimica Acta 403(1):37-41. https://doi.org/10.1016/s0040-6031(03)00122-9

[19] Efremov MY, Olson EA, Zhang M, Lai SL, Schiettekatte F, Zhang ZS, Allen LH (2004) Thin-film differential scanning nanocalorimetry: heat capacity analysis. Thermochimica Acta 412(1-2):13-23.https://doi.org/10.1016/j.tca.2003.08.019

[20] Efremov MY, Olson EA, Zhang M, Schiettekatte F, Zhang ZS, Allen LH (2004) Ultrasensitive, fast, thin-film differential scanning calorimeter. Review of Scientific Instruments 75(1):179-191. https://doi.org/10.1063/1.1633000

[21] Efremov MY, Schiettekatte F, Zhang M, Olson EA, Kwan AT, Berry RS, Allen LH (2000) Discrete periodic melting point observations for nanostructure ensembles. Physical Review Letters 85(17):3560-3563.

[22] Hu L, de la Rama LP, Efremov MY, Anahory Y, Schiettekatte F, Allen LH (2011) Synthesis and characterization of single-layer silver-decanethiolate lamellar crystals. Journal of the American Chemical Society 133(12):4367-4376. https://doi.org/10.1021/ja107817x 
[23] Lai SL, Carlsson JRA, Allen LH (1998) Melting point depression of Al clusters generated during the early stages of film growth: Nanocalorimetry measurements. Applied Physics Letters 72(9):1098-1100. https://doi.org/10.1063/1.120946

[24] Olson EA, Efremov MY, Zhang M, Zhang Z, Allen LH (2005) Size-dependent melting of Bi nanoparticles. Journal of Applied Physics 97(3). https://doi.org/10.1063/1.1832741

[25] Zhang M, Efremov MY, Olson EA, Zhang ZS, Allen LH (2002) Real-time heat capacity measurement during thin-film deposition by scanning nanocalorimetry Applied Physics Letters 81(20):3801-3803. https://doi.org/10.1063/1.1520714

[26] Zhang M, Olson EA, Twesten RD, Wen JG, Allen LH, Robertson IM, Petrov I (2005) In situ transmission electron microscopy studies enabled by microelectromechanical system technology. Journal of Materials Research 20(7):1802-1807. https://doi.org/10.1557/jmr.2005.0225

[27] Zhang ZS, Wilson OM, Efremov MY, Olson EA, Braun PV, Senaratne W, Ober CK, Zhang M, Allen LH (2004) Heat capacity measurements of two-dimensional self-assembled hexadecanethiol monolayers on polycrystalline gold. Applied Physics Letters 84(25):5198-5200. https://doi.org/10.1063/1.1764938

[28] Yi F, LaVan D (2019) Nanocalorimetry: Exploring materials faster and smaller. Applied Physics Reviews 6(3). https://doi.org/https://doi.org/10.1063/1.5098297

[29] Davaji B, Bak HJ, Chang WJ, Lee CH (2014) A novel on-chip three-dimensional micromachined calorimeter with fully enclosed and suspended thin-film chamber for thermal characterization of liquid samples. Biomicrofluidics 8(3). https://doi.org/10.1063/1.4875656

[30] Guenther G, Aulbach E, Hahn H, Guillon O (2011) High-temperature chip calorimeter with atmosphere control. Thermochimica Acta 522(1-2):77-85. https://doi.org/10.1016/j.tca.2011.03.013

[31] Johannessen EA, Weaver JMR, Cobbold PH, Cooper JM (2002) Heat conduction nanocalorimeter for pl-scale single cell measurements. Applied Physics Letters 80(11):2029-2031. https://doi.org/10.1063/1.1457532

[32] Johannessen EA, Weaver JMR, Cobbold PH, Cooper JM (2002) A suspended membrane nanocalorimeter for ultralow volume bioanalysis. IEEE Transactions on NanoBioscience 1(1):29-36. https://doi.org/10.1109/Tnb.2002.806935

[33] Minakov AA, Adamovsky SA, Schick C (2005) Non-adiabatic thin-film (chip) nanocalorimetry. Thermochimica Acta 432(2):177185. https://doi.org/10.1016/j.tca.2005.01.073

[34] Minakov AA, Roy SB, Bugoslavsky YV, Cohen LF (2005) Thin-film alternating current nanocalorimeter for low temperatures and high magnetic fields. Review of Scientific Instruments 76(4). https://doi.org/10.1063/1.1889432

[35] Queen DR , Hellman F (2009) Thin film nanocalorimeter for heat capacity measurements of $30 \mathrm{~nm}$ films. Review of Scientific Instruments 80(6). https://doi.org/10.1063/1.3142463

[36] Suurkuusk J, Suurkuusk M, Vikegard P (2018) A multichannel microcalorimetric system the third-generation Thermal Activity Monitor (TAM III). Journal of Thermal Analysis and Calorimetry 131(2):1949-1966. https://doi.org/10.1007/s10973-017-6684-7

[37] Xu J, Reiserer R, Tellinghuisen J, Wikswo JP, Baudenbacher FJ (2008) A microfabricated nanocalorimeter: design, characterization, and chemical calibration. Analytical Chemistry 80(8):2728-2733. https://doi.org/10.1021/ac702213d

[38] Afridi M, Montgomery C, Cooper-Balis E, Semancik S, Kreider KG, Geist J (2011) Micro hotplate Temperature Sensor Calibration and BIST. Journal of Research of the National Institute of Standards and Technology 116(6):827-838. https://doi.org/10.6028/jres.116.025

[39] Afridi M, Montgomery CB, Cooper-Balis E, Semancik S, Kreider KG, Geist J (2009) Analog BIST functionality for microhotplate temperature sensors. IEEE Electron Device Letters 30(9):928-930. https://doi.org/10.1109/Led.2009.2027038

[40] Afridi MY , Geist J (2010) MEMS Microhotplate temperature sensor BIST: importance and applications. IEEESensor:2159-2160. https://doi.org/10.1109/Icsens.2010.5690549

[41] Dable BK, Booksh KS, Cavicchi R, Semancik S (2004) Calibration of microhotplate conductometric gas sensors bynon-linear multivariate regression methods. Sensors and Actuators B: Chemical 101(3):284-294. https://doi.org/10.1016/j.snb.2004.03.003

[42] Elmi I, Zampolli S, Dori L, Cardinali GC, Nicoletti S, Giovanelli G, Severi M (2005) A low cost transportable instrument based on microsystem technologies for benzene monitoring in outdoor air: a comparative in-field test using a standard GC tool. WIT Transactions on Ecology and the Environment 82:425-434.

[43] Thiery L, Toullier S, Teyssieux D, Briand D (2008) Thermal contact calibration between a thermocouple probe and a microhotplate. Journal of Heat Transfer 130(9). https://doi.org/10.1115/1.2943306

[44] Wheeler MC, Tiffany JE, Walton RM, Cavicchi RE, Semancik S (2001) Chemical crosstalk between heated gas microsensor elements operating in close proximity. Sensors and Actuators B: Chemical 77(1-2):167-176. https://doi.org/10.1016/S09254005(01)00689-X

[45] Yi F, Friedman LH, Chen R, LaVan DA (2019) Sample pattern and temperature distribution in nanocalorimetry measurements. Journal of Thermal Analysis and Calorimetry. https://doi.org/10.1007/s10973-019-08139-2

\footnotetext{
About the authors: Feng Yi is a research chemist in the Materials Measurement Science Division in the Material Measurement Laboratory at NIST, working in nanocalorimetry. Michael D. Grapes was a graduate student at Johns Hopkins University during this work, collaborating with NIST, and is currently a materials scientist in the Materials Science Division, Physical and Life Sciences Directorate, at the Lawrence Livermore National Laboratory. David A. LaVan is a materials scientist, mechanical engineer, and project leader in the Materials Measurement Science Division in the Material Measurement Laboratory at NIST. His work focuses on nanocalorimetry, MicroElectroMechanical Systems (MEMS), and sensors. The National Institute of Standards and Technology is an agency of the U.S. Department of Commerce.
} 